\title{
Do romance à história em quadrinhos: dupla restrição da transposição narrativa*1
}

\section{Du roman à la bande dessinée: double contrainte de la transposition narrative}

https://doi.org/10.34112/2317-0972a2016v34n67p39-50

JeAn-Paul Meyer ${ }^{2}$

Tradução de Adriana Pastorello Buim Arena 3 e Dagoberto Buim Arena ${ }^{4}$

RESUMO: A adaptação de um romance em história em quadrinhos (HQ) constitui para o autor de HQ um paradoxo: conservar na narrativa seu aspecto literário, representando-o por completo em pranchas de imagens percebidas simultaneamente. Por trás desse desafio se encontra a questão mais geral da narração visual. A sequência de imagens narrativas fixas é, como no romance, uma forma moderna da epopeia. Em um e outro, a história passa pela representação imitada de personagens em discurso. A narrativa em quadrinhos é, então, uma representação de eventos, marcada pela linearidade, pela sucessão e pela transformação. Por terem os quadrinhos sua lógica própria, esses princípios sofrem, entretanto, algumas deformações: a narrativa procede da oscilação permanente entre identidade e diferença de quadros justapostos; ela progride de uma imagem à outra pelo encadeamento de enunciados representados. A essa restrição habitual, a transposição de um romance traz uma injunção paradoxal suplementar, marcada pelo duo disposição/

1. ${ }^{*}$ Todas as palavras marcadas por asterisco $(*)$ são notas de rodapé dos tradutores. Optou-se por colocar as referências em notas de rodapé, como fez o autor no original, mas elas são colocadas também no final, para facilitar os estudos dos interessados. Este texto foi originalmente publicado pela revista Formules. Seu original deve ser assim citado: Meyer, Jean-Paul, 2012, Du Roman à la bande dessinée. Double contrainte de la transposition narrative, Formules, 15, 7-18.

2. Université de Strasbourg, Estrasburgo, França.

3. Universidade Federal de Uberlândia, Uberlândia, MG, Brasil.

4. Universidade Estadual Paulista Júlio de Mesquita Filho, Marília, SP, Brasil. 
composição: disposição enunciativa (quadros, balões) que tece o texto fonte; composição icônica (imagem, prancha) que o duplica para criar uma narração visual inédita. $\mathrm{O}$ exemplo de Sem família (de Hector Malot), adaptado por Yann Dégruel, mostra que esse duo, disposição/composição, trabalha a obra como uma restrição produtiva.

PALAVRAS-CHAVE: História em quadrinhos; adaptação; narratividade; restrição; linearidade.

ABSTRACT: For a comic book author, adapting a novel is a paradoxical operation. This one implies to keep the narrative's linear appearance, while representing things in a series of simultaneously perceived picture frames. A challenge that leads us back to the broader issue of visual storytelling. Let's consider the sequence of narrative pictures is - like a novel - a modern form of the epic genre. In both of them, the story involves the imitated representation of characters into discourse. Thus, the picture narrative is representation of events, marked by linearity, succession and transformation. Because comic books have their own logic, these principles will somehow suffer some strain: the narrative proceeds from the constant oscillation between identity and difference in juxtaposed pictures, and its reading proceeds from one image to another through the linking of represented utterances. The transposition of a novel brings to this constraint a further double bind, marked by the opposition between arrangement and composition. On one side, the enunciative arrangement of frames and balloons weaving the source text and on the other, the iconic and frame compositions reflecting a new visual narrative. The example of Sans famille (by Hector Malot) adapted by Yann Dégruel shows that this layout/composition couple is indeed a productive constraint.

KEYWORDS: Cartoons; adaption; narrative; tension; linearity.

Tornou-se impossível considerar o setor da adaptação literária como um fenômeno menor na produção de histórias em quadrinhos. Em primeiro lugar, porque cada vez mais desenhistas, por vezes acompanhados de um autor ou um roteirista de renome, alargam o passo na transposição de uma obra. Em segundo lugar, porque obras de prestígio da literatura mundial estão agora adaptadas como se uma barreira simbólica tivesse sido ultrapassada. Por último, os editores compreenderam que havia o interesse; por isso colocaram adaptações em seus catálogos, criando até coleções especificamente dedicadas a acolhê-las: "Rivages" de Casterman, "Ex Libris" de Delcourt, e muitas outras.

Essa tendência compartilhada pela adaptação em HQ apresenta duas vertentes. Uma se refere ao porquê do fenômeno; diz respeito a seu aspecto externo e aos 
parâmetros que permitem descrevê-lo: busca de legitimidade, moda intelectual, novo segmento de mercado, evolução dos leitores, esgotamento ou "effet de palier* " de gêneros tradicionais etc. Essas características, que interessam às pesquisas em matéria de literariedade e de recepção dos quadrinhos, ou ainda da sociologia de práticas de leitura, não serão abordadas aqui. A outra face do fenômeno, que se refere ao "como", nos interessará mais. Trata-se dos processos de adaptação, seus desvios textuais e visuais, seus efeitos narrativos, e, claro, suas tensões. O que faz um desenhista que escolhe adaptar um romance, senão se impor uma restrição?

A ideia defendida aqui é que a adaptaçãodo romance em quadrinhos (nós falaremos mais de transposição na última parte do estudo) salienta realmente uma injunção paradoxal àquela que o desenhista escolhe para se confrontar. A transposição o obriga a colocar em permanente tensão a estrutura linear da narração (em particular o que preserva da linearidade da narrativa inicial, por exemplo) com a forma composicional - e muito pouco linear - da representação. Tentaremos mostrar, com o exemplo de uma obra particular (Sans Famille, de Yann Dégruel, a partir do original de Hector Malot), que nesse gênero de transposição os quadrinhos se apresentam como uma literatura de (dupla) restrição.

Entretanto, antes de chegarmos ao caso específico da transposição narrativa, nós abordaremos mais amplamente a questão da narrativa em imagens, através de suas características e de suas condições de existência.

\section{NARRAÇÃo E REPRESENTAÇÃo}

Uma sequência de imagens pode ser narrativa? Dito de outra maneira, é possível estruturar uma sequência de imagens de modo que ela produza um discurso que vai resultar em uma história? A questão não é tão trivial quanto parece. Pode-se, com efeito, considerar que a resposta está na pergunta, e que é suficiente examinar a maneira com que uma sequência de imagens fixas representa uma narrativa para provar que isso é possível. Muito menos cômodo é se perguntar, mais profundamente de alguma forma, se uma sequência de imagens pode ou não produzir uma narrativa por si mesma. As teorias da narrativa e as da imagem narrativa têm grandes dificuldades para decidir se a sequência narrativa icônica é narrativa per se ou se ela o é

5. *A expressão effet de palier se refere à ideia de estagnação que pode ocorrer durante um percurso que poderia ser evolutivo. 
por intermédio de uma representação da narração verbal. Para alguns (Bremond ou Barthes, por exemplo, desde os anos de 1960), a narrativa é uma forma cultural geral que se realiza sob vários modos narrativos. Outros, ao contrário, (como Jean-Marie Schaeffer (2007), mais perto de nós ${ }^{6}$ ), veem a narração como um modo exclusivamente verbal e consideram as formas não-literárias da narrativa como representações da história. $\mathrm{O}$ status quo está posto, e ele não se refere apenas aos quadrinhos? Narration proprex Narration procurée ${ }^{* 8}$ é, com efeito, uma oposição à qual o conjunto de narrativas não-verbais está confrontado'.

Voltemos, pois, ao núcleo da questão, ou seja, à interrogação sobre a maneira como a sequência de imagens conta uma história, limitando a área de reflexão ao campo da imagem fixa.

Considera-se, habitualmente, que a narrativa, como uma forma particular de comunicação, se caracteriza pela associação de dois modos relacionais específicos, a representação e a narração. A história em quadrinhos, como as outras narrativas em imagens, pode ser qualificada por estes dois modos ${ }^{10}$. Os trabalhos de Genette, entretanto, mostraram, há muito tempo, a característica problemática da oposição representação/narração. A noção de representação não atinge o estado "puro" senão pela representação dramática, que então não é mais do que uma narrativa propriamente dita. Essa noção de narrativa "pura" só se aplica, no entanto, à narrativa dos acontecimentos. A narrativa de falas às quais os enunciados são reportados foi condenada à imitação fiel, longe da ilusão mimética. Entre a narrativa de eventos e a narrativa de falas apareceu um gênero misto, mistura da diégésis e da mimésis platonianas, chamado epopeia e do qual procede o romance. Esse gênero se caracteriza pelo fato de que em alguns momentos da narrativa "o narrador simula ceder a palavra a seu personagem" ".

Não há dúvida de que a história em quadrinhos é, a exemplo do romance, um herdeiro da epopeia. O discurso nele é reportado, o evento no qual esse discurso se inscreve é mostrado sob a forma imitada, o enunciado do personagem assume a voz do

6. Jean-Marie Schaeffer, Narration visuelle et interpretation. In: Time, Narrative and the Fixed Image/Temps, narration et image fixe, Jan Baetens et Mireille Ribière, ed. (Amsterdam-NewYork: Rodopi, 2001), p. 11-27.

7. Como demonstrado na obra de Raphaël Baroni, La tension narrative (Paris: Seuil, 2007), em particular seu capítulo consagrado ao suspense na história em quadrinhos (p. 327-341).

8. *Narration propre: a narração por ela mesma. Narration procurée: a narrativa derivada de outra narrativa.

9. Pode-se mencionar por memória a controvérsia entre narração figurativa e figuração narrativa que animou a pesquisa em história em quadrinhos nos anos 1970.

10. Na narrativa visual em geral, essa oposição tem frequentemente sido renomeada em mostração e narração.

11. Gérard Genette, Figures III (Paris: Seuil, 1972), p. 192. 
narrador. Nota-se, no entanto, que a história em quadrinhos é uma narrativa em que a parte do mimético éhipertrofiada. A representação icônica afeta a constituição da imagem dos personagens e seu quadro espaço-temporal, bem como a representação dos enunciados linguísticos, ruídos, símbolos dinâmicos e mensagens verbais indiretas endereçadas para o leitor. Ao mesmo tempo, a narração propriamente dita também se refere igualmente à sequência de imagens do encadeamento de enunciados escritos: à organização tabular da prancha responde a ordem dialógica das trocas, geralmente regidas pela disposição de balões. Finalmente, a história em quadrinhos acrescenta a essas características a de constituir um universo de enunciação dividida: o conteúdo dessa fala que o narrador cede ao personagem é usado tanto para a comunicação de personagens entre eles (interlocução é, então, intradiagética) e para a comunicação de informação narrativa dirigida ao leitor (interlocução, então, extradiagética). E por fim, o sistema de referenciação nos quadrinhos é duplo: de uma parte, o locutor é denotado pela palavra que ele profere, enquanto que essa enunciação tem por segunda função a de linearizar a leitura sequencial dos quadros; de outra parte, o locutor é representado pela imagem constantemente repetida que o identifica, enquanto que esta representação faz dele um personagem cujo enunciado veicula a história ${ }^{12}$.

\section{REPRESENTAÇÕES DE EVENTOS}

O desequilíbrio em favor de representação e a constante repetição da imagem do personagem ameaçam a capacidade narrativa da sequência desenhada? Se alguém se refere apenas às categorias tradicionais da narrativa de evento (linearidade, sucessão, transformação), podemos ser tentados a responder de forma afirmativa. Uma sequência ou uma prancha respeita essas categorias, mas de maneira frequentemente infiel. Retomemos esses três parâmetros.

A. Linearidade: a história em quadrinhos é linear, mas não somente isso. Admite-se que um quadro apresentado espacialmente um após o outro se situa, a menos que se sinalize o contrário, igualmente após ele mesmo do ponto de vista temporal. A narrativa em imagens, quando é muito linear, acentua mais do que qualquer outra a ligação causal de vinheta a vinheta; o quadro é a causa daquele que o segue.

12. Na HQ a mostração mascara os aspectos construídos da obra e produz um efeito-narrativo. FresnaultDeruelle vê nisso uma "operação através da qual a representação anuncia, atualiza e torna verossímel a diegese." (Aperçu sur la mécanique narrative des “strips”, Bulletin de Psychologie [XLI/386,1988],p.584-588). 
Entretanto, a ordem de apreensão da informação icônica ou verbal não respeita necessariamente a ordem dos quadros, porque uma restrição visual vinda da composição narrativa da sequência pode contradizer essa ordem. Sabemos que no nível da prancha, essa linearidade é intencionalmente deixada no escuro (como se a cronologia dos acontecimentos pudesse ser maleável) ou ainda que no nível do quadro as vinhetas em justaposição (os inserts) podem materializar a parada ou a recusa da linearidade. Nossa última parte voltará longamente sobre esse ponto.

B. Sucessão: os quadrinhos apresentam uma sucessão de quadros vizinhos, mas com conexões rompidas. Entre dois quadros ou entre duas linhas de quadros, configurado ou não por um interstício branco ${ }^{13}$, um salto no tempo é representado. Ele pode "valer" uma fração de segundo ou representar uma ruptura espaço-temporal completa. O princípio da sucessão, se suspeita, deveria estar a serviço da linearidade, a organizá-la de alguma forma. Ora, a estruturação da prancha da história em quadrinhos aparece frequentemente mais como uma divisão do quadro, que faz da sequência de imagens um grupo de quadros gêmeos em vez de um alinhamento de vinhetas ordenadas. Somos forçados a constatar que o princípio da sucessão na sequência não é sempre garantido pela aparente unidade mínima (o quadro), mas pode se traduzir sob a forma de blocos narrativos, a sequência sendo então composta de tal maneira que a narração em imagens torna o motivo visível, em suma, que a estrutura do evento seja mostrada tanto quanto dita.

C. Transformação: a história em quadrinhos é regida pelo princípio da progressão comum a toda narrativa. $\mathrm{O}$ evento que constitui a história deve evoluir, avançar para um fim, etc., porque a história é télica por natureza. Certamente, a forma romanesca pode violar este princípio de transformação, mesmo que seja apenas para atrasar o efeito (digressão, retrocesso, antecipação...), pois o pressuposto de linearidade e de sucessão é forte o suficiente para que toda ruptura da ordem seja interpretada como uma transgressão passageira. Por outro lado, na história em quadrinhos a contravenção é muito mais limitada, principalmente por causa do nexo de causalidade: a ordem de causa-consequência se superpõe à ordem do antes e do depois. Toda infração deve ser fortemente indicada, a menos que se queira tornar a narrativa deliberadamente enigmática, ou colocar o leitor em

13. A teoria da história em quadrinhos chama-a "espaço intericônico", mas outros nomes foram dados a esta área. O termo gouttière, cada vez mais difundido, vem do jargão bédéologique americano (gutter/calha). ${ }^{*}$ Gouttière equivale a espaço intercônico, espaço entre os quadrinhos como calhas. Bédéologique refere-se ao campo de estudo dos quadrinhos. 
estado de insegurança ${ }^{14}$. Na verdade, a menos que haja intenção declarada de subverter a regra, uma história em quadrinhos não pode conter dois quadros absolutamente idênticos. A narrativa desenhada é télica, mas a unidade narrativa de base é semelfativa ${ }^{15}$.

\section{Algumas restrições “NAturais” Da narrativa em imagens}

Podem-se deduzir da discussão precedente dois elementos constitutivos essenciais de qualquer narrativa em imagens.

O primeiro é que a narração gráfica não tem outro meio senão aquele da relação entre semelhança/diferença para tornar sua narrativa visível. De fato, para que uma sequência de imagens em presença possa ser designada como "sequência narrativa", ela deve reunir aos três parâmetros seguintes:

- as imagens são suficientemente coerentes entre si, para que se as possa relacionar a tudo que as engloba;

- elas são suficientemente diferentes para que se possa detectar uma mudança na passagem de uma para outra;

- a concomitância da coerência de vizinhança e da transformação contígua constrói uma lógica de ação.

Pode-se acrescentar que essa lógica pode vir da própria imagem, como informação divergente: isso será, por exemplo, o fato de que uma personagem andando para a direita, estando próximo do lado direito do quadro parece ir, enquanto aquele que caminha para a direita, estando próximo do lado esquerdo, parece chegar. Esse tipo de informação é, por vezes, convencional, mas o mais frequente é a de ordem semântica, isto é, determinada pela representação mesma ou pelos quadros vizinhos. Em oposição (mas sem ser incompatível com o primeiro tipo) esta lógica de ação pode vir do conhecimento de mundo como informação convergente. É, então, à lógica da experiência que se relaciona a representação imagética.

O segundo elemento constitutivo essencial de qualquer narrativa em imagens, e que aqui ainda faz do princípio de transformação uma restrição inevitável dos

14. Aqui se faz alusão ao incrível efeito que provoca a entrada de Rascar Capac no quarto de Tintin. Ver Hergé, op. cit., p. 32.

15. * Semelfativa: ação que só ocorre uma vez. Em latim, semel significa uma só vez. 
quadrinhos, reside na noção de enunciado. Na medida em que um quadro ou um grupo de quadros representam um enunciado - o que constitui o motor lógico, o mais evidente e o mais comum nos quadrinhos - nenhuma repetição perfeita neles é possível. Não pode haver (salvo artifício) duas enunciações rigorosamente idênticas, nem em nosso uso habitual da língua em discurso, nem no discurso dos personagens da história em quadrinhos. Estes últimos seriam os figurinos de uma "ópera de papel" (a expressão é de Edgar P. Jacobs), suas trocas de falas se caracterizam precisamente pelo fato de que eles são enunciados, imitados e certamente reportados, mas, no entanto, obedecem às mesmas regras de verossimilhança e de coerência interna daquelas que regem a figuração.

Este último ponto testemunha a importância da relação texto-imagem na dinâmica narrativa. É ela, com efeito, que, assegurando o encadeamento de quadros, gera e orienta o movimento de progressão na sequência ${ }^{16}$. Sobre o plano estrutural, a ordem e a disposição de enunciados contribuem para a montagem e para a leitura, linear ou tabular; sobre o plano referencial, os dêiticos conectam os enunciados sobre a situação representada no quadro, enquanto os anafóricos organizam as relações ontológicas entre conteúdos de linguagem e mundo representado.

\section{A TRANSPOSIÇÃo NARRATIVA, UM CASO DE DUPLA RESTRIÇÃO}

Agora é o momento para abordar o tipo muito especial de narrativa desenhada que nos interessa aqui, aquela que se refere às HQ adaptadas de romances. "Adaptação" talvez não seja a expressão adequada, como foi explicado em um estudo anterior ${ }^{17}$. Essas "narrativas de narrativas" não pressupõem qualquer mudança profunda de suporte, nem transformação importante do registro narrativo. Contrariamente à necessária adaptação que impõe a versão televisiva ou a versão cinematográfica de uma obra literária, a versão "HQ" mais perto ou mais familiar do romance, revela mais da "transposição".

16. Ver Jean-Paul Meyer, La référence à la quantité dans les relations texte-image. Préliminaires à un programme de travail, Scolia (20, 2005), p. 259-274, e Trois aspects du décadrage dans la relation texte-image: L'exemple de Maigret tend un piège dessiné par Philippe Wurm, Degrés (133, 2008), p. 1-18.

17. Jean-Paul Meyer, À propos des albums de BD adaptés de romans: De la transposition littéraire à la transposition didactique, in Bande dessinée et enseignement des humanités, Nicolas Rouvière, ed. (Grenoble: Ellug, 2012), no prelo. 
Vimos que na passagem do romance à narração gráfica, uma parte da diegese é responsável pelo conteúdo icônico da imagem e da sequência de quadros; a outra é assegurada pela dupla enunciação do texto dialogado, associada, caso necessário, à voz do narrador que constitui o narrativo. Em $H Q$, no entanto, diz-se igualmente, o dispositivo de quadros em prancha ou em dupla prancha faz com que o olho do leitor perceba elementos narrativos visuais bem antes de sua aparição na condução da narrativa linear. Essa arritmia consubstancial e característica - ela não existe no cinema, por exemplo - é muito semelhante a uma injunção paradoxal para o desenhista. A dupla restrição que se impõe ao se adaptar uma obra literária em história em quadrinhos consiste, com efeito, em transpor um fio narrativo por diversos procedimentos de disposição, enfraquecendo-o permanentemente pelo transbordamento visual que lhe permitem os procedimentos de composição ${ }^{18}$.

Para ilustrar essa dupla restrição, tanto do ponto de vista do duo disposição/ composição quanto do ponto de vista de sua produtividade criativa, nós nos interessamos pelo trabalho realizado pelo desenhista Yann Dégruel em Sem familia de Hector Malot, em uma transposição em seis álbuns ${ }^{*_{19}}$ de 30 páginas ${ }^{20}$. Entretanto, será dada apenas uma visão geral, retomando, para isso, a tríptica linearidade/sucessão/transformação, mencionada antes. É necessário esclarecer que o texto do romance (na edição de bolso integral) representa cerca de 400 páginas, mas os primeiros quatro álbuns da série, que contam a venda e a partida de Rémi, a vida com Vitalis, o encontro com a Sra. Milligan, em seguida, a morte do velho homem, constituem a metade do romance de Malot.

A maioria das pranchas de Dégruel é composta de modo a mostrar transformações importantes de um quadro a outro. A ação é de grande amplitude, acontece muita coisa em cada página. Ao mesmo tempo, a disposição fortemente tabular das vinhetas e dos filactérios - isto é, respondendo a uma lógica representativa própria à sua missão enunciativa habitual - assim como o recurso frequente aos três grandes planos e às incrustações, contrabalançam a "quantidade" de ação, construindo pranchas unidas e homogêneas.

18. Jean-Paul Meyer, Maigret en bandes dessinées : la continuité énonciative au risque d'une narration multifocalisée, Traces $(14,2003)$, p. 235-265.

19. * Livros ilustrados.

20. Yann Dégruel, Sans Famille, após Hector Malot (Paris: Delcourt) ; seis volumes: Mère Barberin (2004), La Troupe du Signor Vitalis (2004), Le Cygne (2005), Neige et loups (2006), La Vache du prince (2007), L'Héritage (2008). 
Se se associa a esse parâmetro de progressão o da sucessão, observa-se ao contrário grande variedade de enquadramentos, a tal ponto que parece quase impossível de encontrar duas pranchas idênticas. Essa heterogeneidade exposta das estruturas é, entretanto, equilibrada pelo fato de que um conjunto recorrente de fenômenos associativos guia a passagem de uma vinheta para outra: contiguidade cromática, harmonia de proporções (partição, proporção áurea, efeito vitral...), distribuições "em gavetas" (grande quadro em coluna vizinha com uma superposição de quadros alongados) etc.

Por último, mas não menos importante, o parâmetro da linearidade foi objeto de muita atenção da parte de Dégruel. Recorda-se de que os efeitos de ruptura da prancha podem ser importantes, devido a mudanças bruscas de planos e reenquadramentos frequentes. Nessas condições, a linearidade da narrativa é difícil de ser realizada. $\mathrm{O}$ desenhista consegue isso por dois meios muito diferentes: um consiste em compor os quadros de maneira clara e explícita, o que compensa o aspecto frequentemente enigmático da prancha; o outro consiste em utilizar o mais frequentemente possível as formas textuais (narrativos e filactérios) como balizas ou como elos sobrepondo os espaços intericônicos, para propor um segmento de leitura. $\mathrm{O}$ interesse da operação é que esse fio de Ariadne não é imediatamente visível; o leitor o procura, o tece mesmo, percorrendo nisso as vinhetas que marcam o caminho.

Nosso estudo consagrado à transposição narrativa nos levou primeiro a especificar o enquadramento geral da sequência de imagens como uma forma narrativa, em seguida, definir as categorias que permitem descrever a narrativa gráfica, e, finalmente, as questões que se colocam para o autor e para o leitor. $\mathrm{O}$ objetivo era o de mostrar que a transposição de um romance em história em quadrinhos reúne as regras narrativas e formais da HQ com as exigências próprias da transposição e impõe ao desenhista uma restrição duplicada. Pode-se pensar, tomando o exemplo da série Sem Família desenhada por Yann Dégruel, que a transposição narrativa é uma forma inesperada, mas bem sucedida de restrição produtiva.

\section{REFERÊNCIAS}

BARONI, R. La tension narrative. Paris: Seuil, 2007.

DÉGRUEL, Y. Sans Famille - intégrale. Paris: Delcourt, 2015. . Mère Barberin. Paris: Delcourt, 2004. . La Troupe du Signor Vitalis. Paris: Delcourt, 2004. . Le Cygne. Paris: Delcourt, 2005. 
. Neigeet loups. Paris: Delcourt, 2006.

. La Vache du prince. Paris: Delcourt, 2007.

. L'Héritage. Paris: Delcourt, 2008.

FRESNAULT-DERUELLE, P. Aperçu sur la mécanique narrative des strips. Bulletin de Psychologie, V. 41, n. 386, p. 583-588, 1988.

GENETTE, G. Figures III. Paris: Seuil, 1972.

HERGÉ. Les 7 Boules de cristal. Tournai: Casterman, 1948.

MALOT, H. Sans Famille. Paris: Dentu, 1878.

MEYER, J.-P. Du roman à la bande dessinée: double contrainte de la transposition narrative. Formules,

n. 15, p. 7-18, 2012. Disponível em: <www.ieeff.org/fismeyer.pdf>. Acesso em: 10 jun. 2016.

. Maigret en bandes dessinées: la continuité énonciative au risque d'une narration multifocalisée, Traces, n. 14, p. 235-265, 2003.

. À propos des albums de BD adaptés de romans: de la transposition littéraire à la transposition didactique. In: ROUVIÈRE, N. (ed.). Bande dessinée et enseignement des humanités. Grenoble: Ellug, 2012.

. La référence à la quantité dans les relations texte- image. Préliminaires à un programme de travail. Scolia, n. 20, p. 259-274, 2005.

. Trois aspects du décadrage dans la relation texte-image: l'exemple de Maigret tend un piège dessiné par Philippe Wurm. Degrés, n. 133, p. 1-18, 2008.

SCHAEFFER, J.-M. Narration visuelle et interpretation. In: BAETENS, J.; RIBIÈRE, M. (ed.). Time, Narrative and the Fixed Image/Temps, narration et image fixe. Amsterdam; New York: Rodopi, 2001. p. 11-27.

\section{SOBRE O AUTOR}

Jean-Paul Meyer é Doutor em Ciências da Linguagem. É docente especialista em Linguística e Didática do Francês na Faculdade de Letras da Universidade de Strasbourg, França. Pesquisa na área de linguística e didática do francês e de semântica nas relações texto-imagem (desenhos animados, ilustrações, imagens didáticas) e didática (gramática, leitura e escrita).

E-mail: jpmeyer@unistra.fr

\section{SOBRE OS TRADUTORES}

Adriana Pastorello Buim Arena possui Graduação em Filosofia, Graduação em Pedagogia, Mestrado e Doutorado em Educação (Universidade Estadual Paulista Júlio de Mesquita Filho), com Bolsa de Doutorado-sanduíche/CAPES (Universidade de Lisboa). Fez estágio pós-doutoral (CAPES 2013/2014) na 
Université Paris-Sorbonne e estágio de formação (2015) na Universidade de Estrasburgo na Faculté des Lettres. É Professora Adjunta da Faculdade de Educação e do Programa de Pós-Graduação em Educação da Universidade Federal de Uberlândia. Tem experiência na área de Educação, com ênfase em Métodos e Técnicas de Ensino, atuando principalmente na área de leitura, de escrita no Ensino Fundamental. Este trabalho teve apoio da FAPEMIG.

E-mail: dricapastorello@gmail.com

Dagoberto Buim Arena possui Graduação em Letras (Universidade Estadual Paulista Júlio de Mesquita Filho), Mestrado e Doutorado em Educação (Universidade Estadual Paulista Júlio de Mesquita Filho), Pós-Doutorado em Educação/FAPESP (Universidade de Évora, Portugal), estágio pós-doutoral em Educação (Instituto Nacional de Pesquisas Pedagógicas de Lyon, França) e PósDoutorado em Letras/FAPESP (Université-Sorbonne, França). Pesquisador convidado na Universidade de Estrasburgo, França. É Livre-docente pela Universidade Estadual Paulista Júlio de Mesquita Filho. Atualmente é professor Adjunto do Departamento de Didática e do Programa de Pós-Graduação em Educação da Universidade Estadual Paulista Júlio de Mesquita Filho, em Marília. Tem experiência na área de Educação, atuando principalmente na área de alfabetização, leitura e conceitos do círculo de Bakhtin em educação.

E-mail: arena@marilia.unesp.br

Recebido em 03 de julho de 2016 e aprovado em o4 de agosto de 2016. 